LEANDRO, José Augusto. Em prol do sacrifício do isolamento: lepra e filantropia na Argentina e no Brasil 1930-1946. História, Ciências, SaúdeManguinhos, Rio de Janeiro, v.20, n.3, jul.-set. 2013, p.913-938.

\title{
Em prol do sacrifício do isolamento: lepra e filantropia na Argentina e no Brasil, 1930-1946
}

\author{
For the sacrifice of isolation: \\ leprosy and philanthropy \\ in Argentina and Brazil, \\ 1930-1946
}

\section{José Augusto Leandro}

Professor do Departamento de História e do Programa de Pós-graduação em Ciências Sociais Aplicadas/Universidade Estadual de Ponta Grossa. Campus Uvaranas

Avenida General Carlos Cavalcanti, 4748

84030-900 - Ponta Grossa - PR - Brasil

joseaugustoleandro@gmail.com

\section{Resumo}

O Patronato de Leprosos, na Argentina, e a Federação das Sociedades de Assistência aos Lázaros e Defesa Contra a Lepra, no Brasil, foram instituições criadas com o objetivo de auxiliar doentes do mal de lázaro e suas famílias. Capitaneadas por mulheres da elite, as entidades, a despeito das singularidades dos seus contextos nacionais, agiram de maneira similar, ambas complementando as políticas de saúde direcionadas à lepra em seus respectivos países. Este artigo pretende demonstrar as semelhanças nas estratégias de atuação das duas instituições filantrópicas que, durante as décadas de 1930 e 1940, agiram em consonância com os médicos defensores do isolamento compulsório.

Palavras-chave: Argentina; Brasil; lepra; filantropia; políticas de saúde.

\section{Abstract}

Patronato de Leprosos, in Argentina, and Federação das Sociedades de Assistência aos Lázaros e Defesa Contra a Lepra, in Brazil, were created as institutions designed to help people with leprosy and their families. Headed by women from the ruling classes, these entities took very similar actions, despite the different national contexts in which they operated, both supplementing leprosy healthcare policies in their respective countries. This article aims to demonstrate the similarities in the strategies adopted by both philanthropic institutions, which, in the 1930s and 1940s, acted in harmony with the physicians who supported compulsory isolation.

Keywords: Argentina; Brazil; leprosy; philanthropy; healthcare policies. 
$\mathrm{E}^{n}$ ndêmicas ou epidêmicas, agudas ou crônicas, as doenças acompanham o cotidiano dos homens através dos séculos. Contudo, também é verdade que a atitude dos indivíduos diante de seus males físicos, bem como o enfrentamento do fenômeno social das doenças, não se dá da mesma forma ao longo do tempo, vindo a adquirir significados simbólicos diversos, consoante o aparato mental de cada época.

O caso da lepra ${ }^{1}$ é exemplar, pois a moléstia foi (e ainda é) capaz de gerar inúmeras representações concernentes à rejeição do doente pelo medo do contágio. Já conhecida na Antiguidade, foi no período da Idade Média que a enfermidade foi identificada, segundo George Rosen (1994), como "a grande praga". Na Europa, na época medieval, "o medo de todas as outras doenças, juntas, dificilmente se pode comparar ao terror da lepra. Nem mesmo a Peste Negra, no século XIV, ou o aparecimento da sífilis, ao final do século XV, produziram tamanho pavor" (Rosen, 1994, p.59). Exageros à parte², fato é que o temor da lepra permaneceria no transcorrer da Idade Moderna e da Idade Contemporânea, quando as explicações de punição divina pelo pecado foram substituídas pela noção de contágio. Na mudança dos tempos, metáforas de guerra também se associaram à doença, e ela se tornou "um inimigo a ser combatido, capaz de liquidar com a sociedade, causando um estado de alarde constante e um sentimento de desconforto para com a figura dos leprosos, sobre os quais pesará a acusação de transportarem uma doença feia e incurável; uma ameaça" (Curi, 2002, p.30).

No que tange à América Latina, a lepra chegou com os colonizadores, sendo desconhecida da população indígena. Documentos dos períodos coloniais fazem referência à doença na Argentina e no Brasil (Quiroga, 1964; Santos Filho, 1977), porém, somente no final do século XIX e, sobretudo, no início do século XX, a moléstia passou a despertar maior interesse na agenda médica. Foi nesse contexto que a lepra passou a ter maior visibilidade nos círculos científicos, o que pode ser observado pela produção de teses acadêmicas da área de medicina sobre a enfermidade e também em artigos assinados por esculápios publicados em jornais de ambos os países. Essa visibilidade refletia um determinado momento na história do conhecimento científico sobre a doença, em que certos aspectos etiológicos da moléstia passavam a ser mais bem compreendidos. Dilma Cabral Costa (2007, p.24-25) resume bem a trajetória científica do período:

O primeiro marco do conhecimento moderno sobre a lepra foi o tratado ilustrado $\mathrm{Om}$ Spedalsked (Um estudo da lepra), publicado em 1847. Nesse trabalho os noruegueses Daniel C. Danielssen e C.W. Boeck estabeleceram as bases clínicas da lepra e tornaramna uma doença clinicamente distinguível. ... As investigações de Danielssen e Boeck sobre a lepra seriam acompanhadas por novas descobertas: em 1863, Rudolf Virchow descreveu a histopatologia da lepra lepromatosa; a descrição completa do bacilo se deu com Hansen, em 1874, e, em 1879, o alemão Albert Neisser comprovou a presença do bacilo em material leproso. ... O século XIX fundou uma nova percepção sobre a lepra, marcada pelo impacto da descoberta do M. leprae e dos pressupostos bacteriológicos, expressos na Primeira Conferência Internacional sobre Lepra, ocorrida em 1897 em Berlim.

De fato, segundo Marcial Quiroga, a formação de uma consciência médico-sanitarista antileprosa mais ativa iniciou-se, na Argentina, a partir das reverberações dessa primeira reunião internacional, que congregou esculápios ao redor do debate sobre a moléstia, na 
Alemanha, em 1897. "Naquele mesmo ano, o Departamento Nacional de Saúde, sob a presidência do doutor José Maria Ramos Mejía, iniciou uma investigação estatística com o objetivo de determinar o número e a distribuição dos casos de lepra no país" (Quiroga, 1964, p.72). ${ }^{3}$ Afirma Quiroga que as conclusões do Congresso de Berlim mantiveram-se latentes no 'espírito' da comunidade médica argentina, levando, inclusive, à organização, em Buenos Aires, em 1906, da Primeira Conferência Nacional da Lepra. No ano da conferência, registrava o diretor de salubridade da província de Buenos Aires, doutor Cesareo Amenedo (1906, p.13): "infelizmente, o número de casos tem-se multiplicado". Somente na sua jurisdição, apontou, havia 144 casos da doença.

Nos vinte anos que se seguiram à conferência de 1906, intenso debate sobre o destino dos doentes do mal de são lázaro entrelaçou médicos e políticos na Argentina. ${ }^{4}$ Vale registrar que, na reorganização do Departamento Nacional de Higiene ${ }^{5}$, em 1911, a lepra ganhou destaque junto ao paludismo, varíola, tuberculose, bócio e cretinismo na Divisão de Sanidade e Profilaxia Terrestre (Veronelli, 1975). Certamente por isso, já no ano seguinte circulava no país o folheto Instrucciones para prevenir y combatir la lepra (Argentina, 1912), publicado pelo Departamento Nacional de Higiene, com o propósito de divulgar a doença e sua forma de transmissão (o folheto mencionava a teoria do médico Baldomero Sommer, equivalente à de Adolpho Lutz acerca da transmissibilidade por mosquitos), bem como as medidas necessárias para desinfecção das casas dos enfermos. Ainda mais significativo: inúmeros anteprojetos de lei tramitaram no Congresso Nacional, após a Primeira Conferência Nacional da Lepra, visando ao controle dos doentes a partir de espaços de segregação (Piñero Garcia, 1935, p.65-68; Guijarro, 1944, p.125). Somente em 1926, porém, foi promulgada a lei n.11.359, conhecida como Lei Aberastury, com vistas à notificação obrigatória dos enfermos de lepra por parte dos médicos e com a proposição de criação de sanatórios-colônia para os doentes considerados contagiantes. ${ }^{6}$

No Brasil, o período entre o final do Oitocentos e início do Novecentos foi crucial para a apropriação da lepra como um problema de saúde pública, tanto por parte dos médicos como do poder público. Na Primeira República, segundo Castro Santos, o Brasil passou pela sua "primeira reforma sanitária", "outorgada pelas elites que controlavam o aparelho de Estado", e "a saúde pública foi instrumental para a modernização da estrutura econômica e administrativa dos estados" (Santos, 2004, p.284). Foi nesse contexto que Oswaldo Cruz incluiu, em 1904, a lepra como doença de notificação compulsória no país. Mais tarde, entre 1915 e 1919, foi criada a Comissão de Profilaxia da Lepra e, em 1920, a Inspetoria de Profilaxia da Lepra e Doenças Venéreas. Com as alterações realizadas na estrutura burocrática da saúde pública a partir de Carlos Chagas, o Brasil passou a contar com regulamento sanitário federal relativo à lepra com vistas à "utilização de força policial para conduzir o suspeito à realização dos exames obrigatórios, ou mesmo para assegurar o isolamento dos doentes" (Cunha, 2005 , p.45, nota 30). Tal regulamento foi objeto de modificações e se tornou definitivo em 1923, com o decreto n.16.300, de 31 de dezembro, cujo sistema de controle consistia na "notificação obrigatória, como prescrita para outras doenças infecciosas; no exame periódico dos comunicantes, como meio de descobrir novos casos; e no isolamento nosocomial em colônias ou mesmo em domicílio, desde que cumprindo uma série de condições" (p.48). ${ }^{7}$

Junto ao redescobrimento da lepra, agora revestida com o manto de grave problema de saúde pública, capaz de "desmoralizar o país" e "invalidar a nacionalidade” (Lisboa, 2002, p.14), 
fato que constituía "vergonha nacional" (Fidanza, 1929, p.6), emergiram iniciativas de assistência aos portadores da doença complementares às providas pelas políticas públicas. Foi nessa conjuntura, entre a década de 1920 e o início da década de 1930, que sugiram, em ambos os países, associações filantrópicas femininas relacionadas especificamente à assistência aos leprosos, associações que se distanciavam, pelo seu caráter burocrático moderno e pela sua articulação intensa com médicos e governantes, de equivalentes anteriores.

No Brasil, em fevereiro de 1926, na cidade de São Paulo, foi fundada a Sociedade de Assistência aos Lázaros e Defesa Contra a Lepra por iniciativa de Alice Toledo Ribas Tibiriçá. Segundo Luciano Curi (2010, p.250), a nova entidade

tratou de incentivar e motivar a criação de inúmeras congêneres pelo país que atuaram diretamente em três grandes objetivos: pressionar o Estado brasileiro a atuar contra a endemia leprótica, auxiliar na viabilização e construção de asilos-colônias para efetivar o isolamento, organizar, dirigir e viabilizar a instalação de preventórios para filhos indenes de leprosos isolados, conforme já constava no Regulamento de 1923.

De fato, congêneres logo foram criadas nas cidades de Santos, Belo Horizonte e no Distrito Federal; localidades mais distantes da pioneira São Paulo, como Parnaíba, no Piauí, e Natal, no Rio Grande do Norte, também formalizaram suas agremiações. Em 1932, como resultado da expansão de instituições com os mesmos objetivos, foi criada a Federação das Sociedades de Assistência aos Lázaros e Defesa Contra a Lepra (FSALeDCL).

A Federação seguiu, a princípio, os ideais autônomos de ação preconizados por Alice Tibiriçá, mas gradativamente se alinhou com o modelo de saúde varguista, implementado de forma mais sistemática após a posse de Gustavo Capanema no Ministério da Educação e Saúde Pública, em 1934. Eleita presidente da Federação, em 1935, Eunice Weaver desempenharia papel preponderante nessa nova fase de relações mais estreitas com o governo federal (Santos, 2006, p.62).

Em julho de 1938, América Xavier da Silveira, vice-presidente da entidade, registrava, entusiasmada, em seu relatório dirigido ao ministro Capanema: "temos nesta data 76 Sociedades filiadas, sendo que o seu número aumenta de mês a mês, graças à ação e ao exemplo das sociedades em pleno funcionamento" (Federação..., 1938, p.10).

Na Argentina, o Patronato dos Leprosos (PL), fundado em 30 de novembro de 1930, seguiu caminhos semelhantes aos da entidade brasileira. Entre seus objetivos declarados estavam a atuação pelo cumprimento da lei n.11.359, o amparo aos enfermos e suas famílias, a colaboração com os governos e médicos para a prevenção da moléstia e o auxílio à investigação científica. Em 1933, a fundadora e presidente da entidade, Hersilia Casares de Blaquier, propalava que velar pelo cumprimento da Lei Aberastury permanecia primordial para a entidade (Patronato de Leprosos, 1933, p.6).

Assim como a instituição brasileira, a argentina, com sede em Buenos Aires, também se organizou, pouco tempo depois de sua criação, em moldes de federação. Dois anos após sua fundação, "com o objetivo de estender sua atuação e levar a obra ao interior da República, ... o Patronato de Leprosos inicia em 1932 a criação de filiais no interior" (Patronato de Leprosos, 1944a, p.315). Em novembro de 1941, por ocasião da Semana da Lepra, o médico Nicolás V. Greco (1942, p.3), em conferência transmitida pela Rádio Municipal, destacou 
que o Patronato contava com a "sede da Capital federal e suas 18 filiais, 16 subfiliais e 150 subcomissões disseminadas em todo o país". No início da década de 1940, as 18 principais filiais do PL estavam localizadas em Rosario, Córdoba, Concórdia, Corrientes, La Plata, Tucumán Salta, Jujuy, Santiago del Estero, Formosa, Resistencia, Santa Fe, Paraná, Mendoza, San Juan, La Rioja, San Luis, Catamarca (Patronato de Leprosos, 1944a, p.315-320).

Este artigo procura contribuir para a historiografia das enfermidades, ao discutir a doença lepra na Argentina e no Brasil, tomando-a em sua articulação com a filantropia. ${ }^{8}$ Vale reforçar, como já vimos apontando, que, desde o início do século XX, ambos os países, em maior ou menor grau, passaram a equacionar a lepra no interior de seus sistemas de saúde pública em construção; e, mais significativo para os propósitos de tomar Brasil e Argentina como uma unidade de comparação, os dois vizinhos, já no início da década de 1930, contavam com organizações de mulheres de elite que atuavam especificamente no combate ao mal de lázaro; organizações ambas federalizadas no mesmo ano, 1932, e que se espraiaram, a partir de então, por diversas partes do território de seus países, vocalizando as virtudes do isolamento compulsório dos doentes considerados contagiantes e a necessidade de criação de espaços preventoriais para filhos indenes de leprosos. ${ }^{9}$

O presente texto procura destacar algumas semelhanças nas estratégias de atuação entre o PL e a FSALeDCL. Portanto, nosso estudo toma duas realidades nacionais em uma mesma época; no caso, dois países vizinhos e que estiveram imersos em um mesmo paradigma filantrópico. O estudo comparado da atuação das instituições entre as décadas de 1930 e meados da década de 1940 permite verificar de que modo cada uma dessas sociedades respondeu a um modelo sanitário internacionalmente reconhecido e adotado na época. ${ }^{10}$ A análise comparada das ações de filantropia voltada para os doentes de lepra no Brasil e na Argentina também permite ampliar o entendimento dos mecanismos intervenientes no complexo do enfrentamento e das respostas sociais à doença. Como afirmaram Nascimento e Santa (2006, p.21-22): "no campo da História das Doenças, o estudo comparado de estratégias nacionais, no combate a moléstias de grande transcendência social ... propicia um conhecimento mais profundo das sociedades em função da sua interação com as doenças que as atingem".

\section{Patronato de Leprosos e Federação das Sociedades de Assistência aos Lázaros e Defesa Contra a Lepra: mulheres pela valorização do isolamento dos doentes}

Desde o início do século XX, na Argentina e no Brasil, crescia a preocupação com o destino dos doentes de hanseníase. Porém, do ponto de vista terapêutico, ainda não haviam sido criados locais específicos para o seu acompanhamento. No Brasil do início do regime republicano, o atendimento aos doentes de lepra diferia muito pouco daquele dos períodos da Colônia e do Império. Os hospitais de lázaros, eram asilos que, "respaldados por medidas policiais, atendiam, a título humanitário, às necessidades mais prementes dos leprosos" (Ornellas, 1997, p.74). Na Argentina, a situação não era diferente nas primeiras décadas do século XX. Os portadores do mal de Hansen, quando diagnosticados, ficavam à mercê de algum possível atendimento em hospitais existentes no país, sobretudo na cidade de Buenos Aires, particularmente no Hospital Muñiz e, em menor medida, em Rosario, no 
Hospital Carrasco. ${ }^{11}$ Segundo David Taber (1937, p.35), em estudo realizado no Hospital Muñiz, em 1926, pelo doutor J.J. Puente, este apontou que na instituição havia cerca de duzentos internados procedentes de diversas partes do país, especialmente da província de Santa Fé.

Assim, à medida que o conhecimento científico reforçava publicamente, e cada vez mais, a lepra como uma doença contagiosa, transmitida por bactéria, crescia, de forma exponencial, entre os setores da elite, a cobrança por uma resposta eficaz por parte do Estado no que tange à proteção da sociedade sadia, passível de contaminação. O próprio Estado passou, cada vez mais, a associar o afastamento de certos grupos de doentes do convívio social à preservação da mão de obra sadia no seu território e ao desenvolvimento e fortalecimento da nação. A eugenia, que penetrou o discurso e a prática de diversos governantes, médicos, educadores e filantropos em ambos os países (Stepan, 2005; Vallejo, Miranda, 2007; Miranda, Girón Sierra, 2009), reforçava a ideia de segregação para os portadores de determinadas moléstias, como a lepra, por exemplo (Monteiro, 1995; Romero, 2002; Miranda, Vallejo, 2008).

As formas de assistência dirigidas aos leprosos nas primeiras décadas do século XX já não poderiam ser vinculadas apenas à caridade religiosa, de acordo com a lógica da compaixão piedosa, na qual "a glorificação do sofrimento alheio" fazia da dor e da miséria "elementos necessários para que o benfeitor [fosse] reconhecido como um agente moral" (Caponi, 2000, p.37). No novo tempo inaugurado pelas descobertas bacteriológicas, qual a maneira mais correta para o gerenciamento de doentes sabidamente contagiosos, como os leprosos? Essa questão passou a imperar entre médicos e autoridades políticas de diversos países desde o final do Oitocentos. A Segunda Conferência Internacional da Lepra, em Bergen (Noruega), em 1909, reforçou uma ideia já presente em Berlim, 12 anos antes, qual seja, o isolamento compulsório dos doentes como solução profilática para a hanseníase. Como bem apontou Bechler (2009, p.200), o isolamento compulsório "a partir destes encontros acadêmicos ganhava o status de recomendação tecnicamente abalizada pelas principais autoridades no assunto naquele período, se transformando, em última análise, num paradigma científico".

No Brasil, a prática do isolamento compulsório dos leprosos por parte do Estado republicano teve seu início oficial em 1924, com a inauguração do Lazarópolis do Prata, no Pará (SouzaAraújo, 1924). Nos anos que se seguiram, Paraná, São Paulo e Rio de Janeiro viram a criação desses ambientes de isolamento, espaços que eram verdadeiras microcidades apartadas das pretensas cidades sãs. No período de 1930 a 1945, segundo Yara Nogueira Monteiro (2003, p.97), a política de saúde brasileira deu grande ênfase à construção, em quase todo o território brasileiro, de leprosários do tipo colônia de isolamento compulsório. Nessa política pública, a conexão entre filantropia e construção de espaços asilares para segregação de doentes é lembrada por Santos (2006, p.64), ao destacar que a Conferência para a Uniformização da Campanha contra a Lepra, organizada pela Federação das Sociedades de Assistência aos Lázaros, entre o final de setembro e o início de outubro de 1933, resultou na "efetiva participação do governo federal na construção de leprosários, permanecendo a sua administração nas esferas estaduais". De fato, os anos seguintes presenciaram um incremento de leprosários, e, ao término da década, América Xavier da Silveira (1939, p.5), vice-presidente da FSALeDCL, registrava: "Existem 41 Dispensários especiais de tratamento de leprosos espalhados no país, 
sem contar com a assistência ministrada nos Centros de Saúde, Ambulatórios, Policlínicas, etc. Até o final do ano de 1939 teremos os 24.000 leitos para os contagiantes".

Na Argentina, a instalação e o funcionamento do sistema do isolamento compulsório foi mais tardia. Se em 1926 já havia sido promulgada uma lei versando especificamente sobre o afastamento do convívio social do doente do mal de Hansen, seriam necessários mais 12 anos para que a primeira colônia de enfermos da doença iniciasse o seu funcionamento. Em 6 de fevereiro de 1938 inaugurava-se o Sanatório Baliña, hospital-colônia de isolamento compulsório na Argentina, localizado em Posadas, província de Missiones, a $1.050 \mathrm{~km}$ de distância da capital, Buenos Aires. A ele, seguiram-se os sanatórios-colônia José J. Puente (San Francisco del Chañar, província de Córdoba), inaugurado em 18 de março de 1939; Maximiliano Aberastury (isla del Cerrito, Chaco), inaugurado em 30 de março de 1939; Baldomero Sommer (General Rodríguez, província de Buenos Aires), inaugurado em 21 de novembro de 1941; e Enrique P. Fidanza (Diamante, província de Entre Ríos, inaugurado em 28 de março de 1948 (Quiroga, 1964, p.111).

A lentidão da Argentina em concretizar o funcionamento dos espaços de isolamento previstos pela Lei Aberastury é um traço distintivo significativo da política pública de saúde do país quando comparada à do Brasil, cuja implementação prática do isolamento compulsório aconteceu já no ano seguinte ao decreto n.16.300, de 1923, com a inauguração do Lazarópolis do Prata, no estado do Pará, em 1924.

Em 1937, em sua tese para obtenção do título de doutor apresentada à Faculdade de Ciências Médicas da Universidade Nacional de La Plata, David Taber (1937, p.42) registrava que era corrente, no público em geral, pelo seu horror à doença, o temor de viver próximo a estabelecimentos que albergassem doentes de lepra. O médico lembrou que a isla del Cerrito, local onde havia sido construído um asilo-colônia, permanecia sem inauguração porque "a opinião pública tem dificultado que seja entregue ao serviço público". De fato, a rejeição à ideia da criação de espaços de aglomerados de leprosos em território argentino foi forte e transparece em textos publicados antes e depois da observação de Taber. O senador pela província de Corrientes Juan Ramón Vidal, ancorando seus argumentos na transmissibilidade da lepra pelo mosquito, discorreu, em 1938, em documento oficial, sobre os aspectos negativos de uma colônia de enfermos na ilha do Cerrito: ali havia áreas "pantanosas" que seriam "criadouros de mosquitos" e, portanto, os vapores que navegariam pelo rio Paraná não estariam seguros quando ali passassem (Província de Corrientes, 1938, p.15); três anos antes, o médico Pedro Piñero Garcia (1935, p.16-18) discursou para a plateia do Rotary Club de Rosario sobre os perigos da instalação de um instituto experimental de lepra com alojamento de enfermos naquela cidade. Conclamou a audiência a se posicionar contrariamente ao empreendimento, pois seria uma espécie de "leproseria" próxima de uma das principais vias de entrada da cidade, e os enfermos, cerca de 80\% indigentes, segundo ele, seriam um "peso" para a assistência da região.

As diversas publicações do PL ao longo da "década infame"12 sempre reforçavam que a instituição havia sido criada com vistas a pressionar o governo para o cumprimento da lei n.11.359. Já em 1933, lamentava Hersilia Casares de Blaquier: "Infelizmente seguimos na mesma situacão... A lei continua sem tomar seu definitivo caminho" (Patronato de Leprosos, 1933, p.6). No mesmo ano, o doutor Pedro Baliña (1933, p.7), em texto dirigido à Academia Nacional de Medicina, afirmou, categoricamente, que quem obstaculizava o cumprimento da 
lei n.11.359 era o próprio povo argentino, "em parte diretamente e em parte por intermédio das autoridades que elege, entre elas as das comunas e as provinciais".

Portanto, vale destacar que o PL não encontrou um terreno previamente bem pavimentado em torno da ideia e da prática do asilamento compulsório, fato de alguma forma já desenvolvido no Brasil ao iniciar-se a década de 1930. O PL teve de adicionar sua contribuição privada às políticas públicas da lepra na Argentina ao mesmo tempo em que teve de agir como o principal militante, no país, para o cumprimento da Lei Aberastury. Registrou Luis Arguello Pitt (1942, p.149-150), em 1942, em sua tese de doutorado em medicina sobre a lepra em Córdoba: "É necessário enfatizar que o Patronato como fator de colaboração com as autoridades sanitárias ocupa na campanha antileprosa um papel preponderante. Esse papel é complemento indispensável do que podem fazer o governo e os médicos em favor dos enfermos. Certos fatos e situações só podem ser contemplados pela ação privada, traduzida pela obra do Patronato". Pitt não estava exagerando ao utilizar a expressão "papel preponderante", uma vez que os setenta casos de observação de pacientes que compuseram sua tese de medicina foram coletados no Dispensário Dr. Francisco de La Torre, criado em 1939 por iniciativa da filial Córdoba do PL. Sobre a criação do dispensário, ironizou o esculápio: "parece que isso deveria ser uma função do Estado" (p.33).

Assim, para "buscar por todos os meios possíveis que a lei n.11.359 fosse cumprida" (Patronato de Leprosos, 1944b, p.7), outra diferença a pontuar em relação às duas instituições diz respeito ao fato de que a presença do PL no espaço público da rua foi, aparentemente, mais agressiva e constante se comparada com a da FSALeDCL. No Brasil, foi evidente o alinhamento de Eunice Weaver às políticas de saúde a partir do momento em que assumiu a presidência da Federação, em 1935, e não houve atritos entre FSALeDCL e as diversas instâncias governamentais. Vale registrar que nesse alinhamento da entidade com Capanema e Vargas, significativos recursos monetários do governo foram disponibilizados para a Federação. Tal fato foi registrado por contemporâneos da filantropa como a norte-americana Elizabeth Meredith Lee (1970, p.47) ${ }^{13}$, que, ao publicar um livro sobre missionários metodistas na América Latina, destacou que a partir de 1935 a Federação, tendo Eunice à sua frente, passou a contar com auxílio anual de cerca de 150 mil dólares do governo.

Se, a partir de Capanema, as relações entre as mulheres brasileiras envolvidas com a filantropia aos leprosos e o governo central se transformavam em relações profundamente amistosas, na Argentina, por seu turno, continuava existindo certo ruído opondo as mulheres de elite envolvidas com assistencialismo aos doentes e o governo. Tal ruído era resultado do não cumprimento da lei n.11.359 e, particularmente, era associado à falta de unidade e coesão nacional em torno da construção de espaços hospitalares para isolamento de portadores do mal de lázaro. A oposição dos governos das províncias do país à presença de espaços de segregação de doentes de lepra em seus territórios foi constante durante a maior parte da década de 1930 e quase inviabilizou a utopia disciplinar do isolamento, colocado em prática pouco antes do alvorecer da década de 1940. Entretanto, se houve 'ruído' entre mulheres de elite e governo em torno do assistencialismo aos leprosos na Argentina, não gerou desconforto entre eles. Pelo contrário, o PL sempre foi amistoso com as autoridades do governo central e, em certas solenidades que organizou, contou com a presença do presidente da República, general Agustín P. Justo. A primeira dama do país entre 1932-1938, Ana Bernal 
de Justo, também prestigiava as atividades da instituição e era uma das 39 'conselheiras' da instituição em 1935 (Patronato de Leprosos, 1936, p.4). E, mais importante, a entidade recebia subsídios do governo. O Congresso Nacional, na lei orçamentária de 1935, por exemplo, destinou a contribuição de 100 mil pesos para o PL, e o Ministério das Relações Exteriores e Culto contribuía com pequenas somas de dinheiro para distribuição às filiais (Patronato de Leprosos, 1936, p.27).

As instituições privadas se assemelharam profundamente nas suas maneiras de atuação complementar às políticas públicas de então. As semelhanças foram francamente mais fortes do que as diferenças, vale dizer, porque as instituições navegaram na mesma rota para o equacionamento e o enfrentamento da moléstia, qual seja, a mobilização social pelo medo do contágio. As entidades agiram pautadas pelos preceitos dos médicos isolacionistas que compunham os seus quadros. O Conselho Técnico da Federação, em 1943, incluía 11 famosos leprologistas, entre eles Souza-Araújo, Ernani Agrícola e Barros Barreto (Revista de Combate à Lepra, mar. 1943- jun. 1944); a Comissão de Médicos do Patronato, no mesmo ano, era composta por mais de 11 esculápios, entre eles Baliña, Schujman e Fernández (Patronato de Leprosos, 1944a), já famosos no campo da leprologia, e outros como Gregorio Aráoz Alfaro, notório por sua atuação no campo da tuberculose, da puericultura e uma das personalidades centrais no eugenismo argentino (Vallejo, 2009, p.184). Na busca constante do fortalecimento da nação pela valorização e proteção do corpo sadio de seus membros, PL e FSALeDCL amplificaram as virtudes do isolamento dos doentes em espaços apartados da sociedade imaginada como sã. Uma das mulheres da comissão diretiva do Patronato do início da década de 1930 chegou a afirmar na Rádio Fénix que, devido ao fato de a lepra ser de "fácil propagação", ao enfermo da doença devia ser "imposto o sacrifício do isolamento total e absoluto, para o bem de seus semelhantes" (Patronato de Leprosos, 1933, p.49).

A filantropia feminina brasileira daquele momento agiu no sentido de valorizar a ideia e a prática do isolamento, fosse ele domiciliar, para as formas consideradas não agressivas da doença, ou nosocomial, para as formas consideradas contagiosas. ${ }^{14}$ A partir do ministério Capanema, a prática do isolamento em colônias seguiu com bastante força, e "o ritmo centralizador imposto pelo Plano Nacional de Combate à Lepra, iniciado em 1935, ampliou medidas coercitivas em relação à moléstia por parte do governo federal", medidas essas que foram, em maior ou menor grau, seguidas pelos diversos estados da federação (Leandro, 2009, p.444).

$\mathrm{Na}$ Argentina, a atuação das mulheres de elite filantropas com vistas à valorização do isolamento dos doentes é explícita nos diversos documentos gerados pelo PL, desde seu início, uma vez que uma das principais razões da existência da entidade era atuar pelo cumprimento da Lei Aberastury. Um ano antes de o país possuir sua primeira colônia de isolamento compulsório, o PL publicou um livro com o resultado de um concurso literário patrocinado pela entidade em 1936, direcionado para toda a nação argentina, "com o objetivo de estimular a produção literária que aviva a simpatia e a compaixão pelo sofrimento humano" (Patronato de Leprosos, 1937, p.11). O ensaio "El leproso y la sociedade", escrito por M.I. Franzini Herrera de Fernández (1937), apesar de não ter sido o vencedor em sua categoria, foi destacado como 'primeira menção'. No texto, o autor narrou as dificuldades de implementação de espaços de segregação no território argentino e valorizou a atuação do PL na busca desse 
ideal: "Como resposta mágica a esse duplo clamor dos enfermos e de seus médicos, surgiu o Patronato de Leprosos. E fez-se uma mão estendida com carinho. Um coração generoso que soube 'compreender'... É necessário levantar asilos!” (p.45).

\section{A filantropia no tripé e o tripé da filantropia}

Em estudo sobre entidades filantrópicas e políticas públicas no combate à lepra no Brasil, Vicente Saul Moreira dos Santos (2006, p.51) aponta que a criação das Sociedades de Assistência aos Lázaros e Defesa Contra a Lepra, na década de 1920, foi um marco nas "relações entre as entidades assistenciais [laicas] e os poderes públicos". No início, essas entidades mantiveram alguma autonomia decisória em face do governo central; porém, na gestão de Gustavo Capanema frente ao Ministério da Educação e Saúde (1934-1945), as diretrizes das instituições foram-se alterando no sentido de mais aproximação às políticas públicas. Para o autor, a atuação das entidades filantrópicas laicas no período ainda segue "pouco estudada pela historiografia brasileira, tanto no que concerne ao papel que desempenharam na formação de políticas públicas de saúde como no tocante aos movimentos sociais protagonizados por mulheres" (p.54).

Com efeito, ao nos debruçar sobre documentos diversos produzidos pelas instituições filantrópicas ligadas à lepra capitaneadas por mulheres de elite argentinas e brasileiras, é possível afirmar que todas atuaram em permanente contato com médicos e autoridades do governo, auxiliando na moldagem das políticas públicas de então. O PL e a FSALeDCL podem ser incluídos na observação de Yolanda Eraso (2009) quanto à importância do papel das mulheres para a configuração da assistência social na América Latina nos séculos XIX e $\mathrm{XX}$. Elas, segundo a autora, não foram apenas consumidoras, mas protagonistas importantes na configuração da administração daquilo que vem sendo chamado de economia mista de assistência social, uma espécie de terceiro setor delineado antes mesmo e durante a emergência do Estado de Bem-Estar Social. ${ }^{15} A$ agência feminina foi fundamental nessa configuração e frequentemente se construiu a partir de várias "interações com outros atores sociais, isto é, médicos, clérigos, políticos, governantes" (p.9-10). Os novos estudos sobre a assistência social em países da América Latina indicam, segundo a autora, "que a relação mulheres e assistência social e mulheres e Estados de bem-estar ocuparam no contexto latino-americano um papel muito mais relevante e complexo do que aquele que previamente havia sido designado como práticas tradicionalistas" (p.23).

Ao longo da década de 1930 e parte da década seguinte, período fértil de atuação das mulheres do PL e da FSALeDCL, prevaleceu uma política de saúde para a lepra que a literatura denominou modelo tripé. Para o Brasil, Laurinda Maciel (2007, p.18) resumiu com propriedade esse modelo: "era amparado no funcionamento conjunto de três instituições que procuravam cercear a doença, o doente e os que com ele se relacionavam: o leprosário visava isolar e tratar o doente; o dispensário tratava dos comunicantes, normalmente familiares e os que com o doente haviam mantido contato; e, por fim, o preventório, que separava, desde o nascimento, se possível, os filhos dos pacientes isolados". Da mesma feita, a profilaxia da doença na Argentina também buscou pautar-se no mesmo modelo tripé. Tal política de saúde colocou as mulheres de elite dos dois países em mobilização filantrópica constante, 
sobretudo aguçando-as a atuar em uma das partes do tripé, o preventório. Nesse caso, o papel da mulher-mãe-protetora da família era perfeitamente transferido para as atividades assistenciais de então. Sobre o agir da mulher na configuração da família, Hersilia Casares de Blaquier, em seu discurso no evento de fundação da filial do Patronato em La Plata, em outubro de 1933, afirmou:

\section{Senhoras:}

A mulher é o sal misterioso que impede a família de ser corrompida. A família não é outra coisa senão o que a mulher dela faz. Ela é quem a resume. É o grande motor da sua moralidade ou de sua corrupção. E é a mulher que se levanta em proteção aos que sofrem de lepra, de suas famílias indigentes e em defesa da sociedade civil que é a reunião de famílias reagrupadas em torno de um chefe político (Patronato de Leprosos, 1933, p.35).

É possível afirmar que o próprio assistencialismo feminino argentino e brasileiro relacionado ao mal de lázaro, foi erigido, ele também, a partir de três partes interconectadas: divulgação pública da doença; realização de campanhas para coleta de dinheiro e/ou bens diversos para a causa da lepra; controle e gerenciamento dos espaços destinados aos filhos dos leprosos.

Quanto à divulgação pública da doença lepra, as entidades aqui analisadas, junto aos diversos setores ligados aos médicos de seus respectivos países (universidades, departamentos de saúde pública e associações de classe), podem ser consideradas as vozes amplificadoras do discurso sobre a presença assustadora de um mal medieval no território sul-americano. ${ }^{16}$ Eunice Weaver e Hersilia Casares de Blaquier viajaram por diversas regiões de seus países e realizaram palestras e encontros sociais com os representantes das municipalidades locais e suas mulheres, com religiosos e demais membros das elites das cidades por onde passaram. Certamente, nesses encontros, a máxima do médico argentino Alfredo Verano (1938) - "para uma grande pátria um povo saudável" - acompanhava as oradoras no momento em que discursavam pelas vantagens da criação de novas entidades, as quais seriam filiadas à federação por elas controladas. Weaver chamava atenção para o grande perigo da contaminação da nação caso a sociedade não se mobilizasse, pois a lepra, doença "que em sua hediondez nenhum mal a supera", havia invadido o país de "Norte a Sul" (Alvarenga, 2011, p.31). Casares de Blaquier, por seu turno, conclamava as mulheres do Patronato a "levantar o grito contra a inércia das autoridades" em cujas mãos estava o cumprimento da lei n.11.359, pois essa atitude salvaria o país "de seguir os passos da Índia, impotente hoje perante o espantoso progresso da lepra" (Patronato de Leprosos, 1933, p.12).

As publicações do PL e da FSALeDCL demonstram o elevado grau de interação das filantropas com as autoridades médicas, educacionais e governamentais em geral; ilustram também um certo protocolo de prestação de contas referente às atividades realizadas ao longo dos anos. No Brasil, o Boletim da Sociedade de Assistência aos Lázaros começou a circular em 1929, e, em 1936, a Revista de Combate à Lepra passou a se apresentar como o órgão oficial da FSALeDCL. Na Argentina, o Patronato de Leprosos passou a editar suas Memórias já em 1931 e, em 1938, criou a revista Presente, publicação nos moldes das revistas femininas populares da época, veículo no qual constantemente eram divulgados 
eventos beneficentes para a causa da lepra, com ampla exposição dos membros da elite portenha. Fotografias diversas registram atividades sociais as mais variadas em benefício do PL, como encontros nos 'magníficos salões' do Clube Social de Bridge, concerto da cantora francesa Lys Gauty no Teatro Casino de Buenos Aires (Patronato de Leprosos, 1939, p.12, 26-27), concurso de hipismo "nas magníficas canchas do campo de Hipismo Militar Argentino" (Patronato de Leprosos, 1941, p.11), entre outros eventos.

Mas vale lembrar que, além da comunicação com setores 'ilustrados' da sociedade, havia também a necessidade de as filantropas comunicarem-se com um amplo público pouco esclarecido quanto à presença da doença nos seus países e os possíveis caminhos para o seu combate. Assim, visando atingir uma audiência maior do que a atingida pelos boletins, revistas, folhetos e outras publicações impressas, tanto as filantropas do Brasil como as da Argentina lançaram mão do rádio como um veículo de amplo alcance para a divulgação dos seus ideais. Palestras radiofônicas realizadas pelas integrantes do PL e da FSALeDCL foram constantes, e as entidades também convidavam ilustres cientistas para dissertar sobre determinados aspectos ligados à doença. No Brasil, antes mesmo da liderança de Eunice Weaver, autoridades médicas já discorriam sobre a doença em eventos sociais diversos. Em 1932, por exemplo, Adolpho Lutz falou ao microfone da Rádio Sociedade do Rio de Janeiro sobre o papel do mosquito na trasmissão da lepra nos países de clima quente, como o Brasil. O eminente médico, que, segundo historiadores das ciências, seguiu convencido, até a sua morte (em outubro de 1940), da importância do inseto como elemento transmissor da doença (Benchimol, Sá, 2003, p.50), iniciou sua fala agradecendo o "gentil convite da Sociedade de Assistência aos Lázaros e Defesa contra a Lepra", pela oportunidade de "tecer algumas considerações em redor do magno problema sanitário ... examinando-o, principalmente do ponto de vista da transmissão e profilaxia" ${ }^{17} \mathrm{O}$ poder de penetração do rádio em amplas partes do território brasileiro, aliado ao poder de oratória de Eunice Weaver em suas campanhas em prol da Federação, foi lembrado por colaboradores da filantropa como de grande importância no sentido de influenciar as pessoas a decidir pela internação ${ }^{18}$ (Federation..., 1951, p.15).

$\mathrm{Na}$ estratégia de educação sanitária do período varguista, as questões de profilaxia e tratamento da lepra foram destacadas e, conforme observou Laurinda Maciel (2007, p.142), “o rádio foi um dos veículos de maior eficiência na difusão de um projeto político e pedagógico do Estado Novo". Segundo a pesquisadora:

As palestras através do rádio objetivavam levar ao conhecimento da população as atividades desenvolvidas pelo SNL [Serviço Nacional da Lepra] em relação à profilaxia e tratamento da lepra. ... Durante 1944 e 1945, os temas principais abordados nestes pronunciamentos foram: esclarecimento quanto aos tipos de preventórios existentes no Brasil e critérios para internação das crianças; balanço das ações federais de combate à lepra; a rede de leprosários do país; a necessidade e importância de o paciente procurar espontaneamente tratamento especializado; a assistência social às famílias e a importância de ampará-las, além de estratégias utilizadas pelo governo para combater a doença nos diferentes Estados e a produção de livros especializados em leprologia (p.143).

$\mathrm{Na}$ Argentina, foram constantes os discursos veiculados sobre a lepra nas diversas estações radiofônicas do país. Pela voz de autoridades médicas ou das próprias mulheres do Patronato, 
inúmeros aspectos da doença atingiam amplas audiências no país. Na Semana da Lepra, evento anual nas décadas de 1930 e 1940, Hersilia Casares de Blaquier e demais representantes das filiais do PL do interior do país, sempre que possível, se manifestavam sobre o andamento das atividades da entidade em 'conferências radiofônicas'. Somente na capital federal, nos primeiros anos da década de 1940, 18 estações radiodifusoras comentavam frequentemente a obra do Patronato: Argentina, Belgrano, Buenos Aires, Cultura, Del Estado, Del Pueblo, El Mundo, Excelsior, Fénix, La Voz del Aire, Libertad, Mitre, Municipal, Porteña, Rivadavia, Splendid, Stentor, Agencia Informativa Andi (Patronato de Leprosos, 1944a, p.269).

As mulheres do PL certamente miravam o exemplo dos homens da Sociedad Argentina de Eugenesia que, em 1931, com as transmissões do programa radiofônico Clamor, atingiam vastíssimas e diversificadas audiências. Gustavo Vallejo (2009, p.187), que pesquisou tal programa, informa que o público estimado de ouvintes da primeira transmissão que foi ao ar, em novembro daquele ano, superava 500 mil em todo o país. Para o historiador, “O rádio era o meio através do qual a inquestionável autoridade científica penetrava os lares, especialmente atingindo aqueles suspeitos de maus hábitos - morais e sanitários. E fazia isso de uma maneira bastante mais simples do que outras ações empreendidas pelo higienismo finissecular" (p.184).

O PL, ao manifestar-se por palestras radiofônicas ou por rápidas propagandas da entidade, seguia em seu objetivo de chamar atenção da sociedade para a causa da lepra, e o veículo de comunicação propiciava, de fato, que as ideias das filantropas atingissem amplas audiências, em diferentes lugares. Com argúcia, observou Alberto J. Aguirre (citado em Haussen, 1997, p.81) que na Argentina da década de 1930 "vivia-se apaixonadamente o rádio" e decidir ouvir a Belgrano, a Splendid ou a El Mundo era como decidir ser torcedor do Boca ou do River.

A filantropia feminina brasileira e argentina em torno do mal de lázaro explicitou uma certa tradição das elites urbanas sul-americanas no atendimento às necessidades dos mais carentes, em especial nas questões de saúde. Porém, ao divulgar publicamente e de diversas maneiras a doença, essas elites acabaram por granjear, na era republicana, amplo poder de vocalização junto às camadas médias e pobres das cidades. No caso da lepra, a voz da filantropia feminina não apenas tornava didática a história e as formas de contágio da doença, mas, sobretudo, divulgava as vantagens sociais do isolamento, convalidando dessa forma tanto o discurso médico quanto a política de saúde (já implementada ou em vias de implementação) para a lepra naquele momento.

Quanto às campanhas para coleta de dinheiro e demais bens para a causa da lepra, as filantropas miravam não apenas a aquisição de roupas e alimentos para os leprosos e suas famílias, mas, sobretudo, a obtenção de dinheiro para construção e/ou ampliação de infraestrutura relacionada a algum aspecto do tripé dispensário-leprosário-preventório. FSALeDCL e PL realizaram, desde o início de suas fundações, atividades constantes visando a tais fins. Essas campanhas eram veiculadas a partir de folhetos, cartazes, palestras em espaços de outras entidades, como o Rotary Club, por exemplo, e, evidentemente, em radiodifusoras. Buscavam mobilizar a sociedade por meio da caridade cristã, indicando que o gesto de doação deveria ser concentrado nas entidades que, de acordo com seus critérios, repassariam o que fosse arrecadado aos doentes e suas famílias, ao governo federal, estadual, das províncias e das municipalidades. ${ }^{19}$ 
No Brasil da Primeira República e era Vargas eram pouquíssimos os estados da federação que contavam com uma elite rica disposta a colaborar com dinheiro para questões de saúde pública. Para o Rio de Janeiro, há o exemplo de Guilherme Guinle e, para São Paulo, Julio de Mesquita (Sanglard, 2008; Monteiro, 1998, p.12) ${ }^{20}$; a maioria dos estados da federação não possuía uma elite acostumada a tal prática. Assim, a presença da presidente da FSALeDCL em lugares remotos do país, e aparentemente com menos recursos financeiros, era fator indispensável para obtenção de recursos privados para a causa da lepra. No Piauí, por exemplo, Antonia Alvarenga (2011, p.160 et seq.) demonstrou como a visita de Eunice Weaver, em agosto de 1941, foi fator de mobilização das "rodas sociais" e do "corpo médico da capital" no sentido de angariar doações expressivas da elite piauiense para a construção de um preventório no estado.

Essas campanhas para obtenção de fundos, levando-se em consideração a grande quantidade de colônias de isolamento compulsório no Brasil, auxiliavam o Estado na construção de igrejas e capelas nesses espaços de segregação e, com o dinheiro arrecadado pela FSALeDCL, também construíam-se ou equipavam-se cineteatros, espaços esportivos e bibliotecas nos leprosários brasileiros. No período de Alice Tibiriçá à frente da Federação, entre 1932-1935, o dinheiro arrecadado pela entidade auxiliou na construção de pavilhão de convalescentes na colônia Pirapitingui; em dispensário na capital de São Paulo; em pavilhão de diversões na colônia Santa Isabel em Minas Gerais e na colônia Curupaiti, em Jacarepaguá, no Rio, entre outros exemplos (Santos, 2006, p.66). Demais contribuições das sociedades filiadas à Federação poderiam ser aqui exemplificadas, todas elas relacionadas à criação ou manutenção, nas colônias de isolamento compulsório, de pequenas fábricas para trabalho dos internos, bibliotecas e grêmios culturais, pavilhões de diversões com dependências recreativas e canchas desportivas de bola ao cesto, futebol, voleibol etc. A partir de Weaver, as chamadas Campanhas de Solidariedade, organizadas pela Federação, voltaram-se, sobretudo, para obtenção de dinheiro destinado à construção de preventórios. Iniciaram por Pernambuco, onde, em 1936, foram arrecadados fundos para construção do preventório da cidade de Recife. Também nesse ano realizaram-se campanhas no mesmo sentido na Paraíba, na Bahia, no Espírito Santo e em Santa Catarina; no ano seguinte, no Rio de Janeiro, Ceará e Maranhão; em 1938, no Rio Grande do Sul e, em 1939, a Federação realizou “campanhas pró-construção de preventórios em 10 cidades da Zona da Mata, em Minas, para a construção do Preventório de Juiz de Fora, que iria atender a essa vasta região" (Federação..., 1945, p.13-17). America Xavier da Silveira (1939, p.22) contabilizou:

A Federação das Sociedades de Assistência aos Lázaros e Defesa Contra a Lepra conta hoje [em 1939] com quase cem filiadas em todo o Brasil e vem seguindo o programa que traçou de colaborar com os poderes públicos, em estreita cooperação com as autoridades sanitárias na propaganda e educação, visando ao combate à lepra em todo o país. A Federação em suas Campanhas de Solidariedade já angariou 3.000:000\$000 rs. nestes três últimos anos de atividade - 1936 a 1939 - cooperando para esse resultado as suas filiadas.

Na Argentina, as mulheres filantropas fizeram campanhas de arrecadação de dinheiro para a causa da lepra que impressionam pelo grau de organização, mobilização e impacto social, sobretudo na capital. Na Semana da Lepra de 1942, por exemplo, as argentinas do PL tomaram 
a cidade Buenos Aires, organizadas em comissões e subcomissões que garantiram a presença das representantes da entidade, em busca de contribuição monetária, em 67 ruas do Centro e em seis bairros; ainda na mesma semana daquele ano, com o mesmo propósito, 16 localidades próximas da capital, como Tigre, Quilmes, San Isidro, entre outras, também contaram com a presença, em suas ruas, de senhoritas e senhoras do PL (Patronato de Leprosos, 1944a, p.1517). A documentação gerada pela instituição registrou esses eventos desde 1931 até, pelo menos, meados da década de 1940; a campanha de arrecadação de dinheiro normalmente acompanhava e era articulada à Semana da Lepra, período em que as mulheres saíam pelas ruas, carregando vasos em formato de coração e pedindo a gentil contribuição da população argentina - pelo menos dez centavos - para a causa da doença. Além disso, caixas especiais para depósito de dinheiro (alcancías) circulavam durante o ano todo em escolas, hospitais, igrejas, bancos, teatros, cinematógrafos, fábricas, farmácias, clubes, estações de estrada de ferro e demais locais onde a comissão de coleta, sob a direção da senhora Elvira Bonorino Udaondo de Sojo, decidisse (Patronato de Leprosos, 1944a, p.233).

O dinheiro arrecadado pelo PL foi suficiente para a criação de uma considerável infraestrutura relacionada à doença no país. O Dispensário e Laboratório Experimental de Lepra, em Buenos Aires, inaugurado em outubro de 1935, foi a primeira grande obra realizada com recursos do PL. A ela seguiram-se outras referentes à construção de pavilhões específicos para enfermos, tanto no hospital Muñiz, em Buenos Aires, quanto no hospital Carrasco, em Rosario, e, mais tarde, no Hospital Avellaneda, em Tucumán; um pequeno leprosário com cinquenta camas em Formosa e dispensários criados em outras localidades, como Resistencia e Barranqueras, também contaram com auxílio do dinheiro arrecadado pelas filantropas. Somente para a criação dessa infraestrutura, o Patronato contabilizava que já havia investido, até o final do ano de 1939, mais ou menos a soma de 400 mil pesos (Casares de Blaquier, 1939, p.15-21). Ainda, as filantropas utilizaram suas verbas no financiamento de viagens para médicos estagiarem em instituições relacionadas à lepra no exterior, como o Leprosário de Carville, na Louisiana (EUA), e leprosários brasileiros, especialmente os paulistas. Até mesmo no custeio da preparação e distribuição de medicamentos, como o óleo de chalmugra, por exemplo, envolveu-se o PL.

Em 1937, iniciaram-se a preparação de remédios em grande escala e seu envio gratuito para todas partes da República. O Patronato de Leprosos, apesar das dificuldades, tem conseguido armazenar o óleo de que os enfermos necessitam, encomendando-o diretamente da Índia. O óleo e outros medicamentos são preparados e fracionados nos laboratórios da instituição, estocados no depósito de remédios e depois distribuídos gratuitamente aos leprosários e aos enfermos, uma vez solicitados diretamente pelos médicos (Patronato de Leprosos, 1944a, p.225).

E, assim como a FSALeDCL, que recebeu contribuições diversas de diferentes empresas - Companhia de Cigarros Souza Cruz, Moinho Inglês, Banco Moreira Salles, Casa SuissoBrasileira, entre outras (Santos, 2006, p.75) -, o PL contou com donativos diversos de diferentes empresas: a General Motors doou para a instituição, em 1936, um automóvel Chevrolet Sedan de quatro portas; no mesmo ano, a Farmácia Franco Inglesa doou 500g de azeite de chalmugra e a Cia. Grapp S.A., de Blumenau, no Brasil, "uma casinha de madeira com dois dormitórios, banheiro e corredor" (Patronato de Leprosos, 1944b, p.41). Em outros anos, diferentes firmas 
são citadas com "doações diversas": Cervecería Quilmes, Frigorífico Anglo, Matarazzo \& Cia, Casa Kodak, Nestlé Argentina, para citar alguns exemplos (p.42-43).

Por fim, como parte fundamental do tripé de atuação das entidades, cabe mencionar o controle e gerenciamento dos espaços destinados aos filhos dos leprosos: ideal perseguido insistentemente tanto pela FSALeDCL como pelo PL e concretizado na intensa mobilização das mulheres argentinas e brasileiras pela viabilização e valorização dos preventórios. No Brasil, esses espaços

tinham a função de abrigar as crianças sadias, filhas de pais leprosos, que eram separadas logo ao nascer, evitando que se tornassem, através do contato, novos casos da doença. Além disso, a instituição era responsável pela criação e educação dessas crianças, até a maioridade. Os preventórios poderiam ser construídos anexos aos leprosários ou de forma independente. A tarefa de proteção das crianças, considerada benemérita, ficou a cargo, no Brasil, de associações privadas mais conhecidas como Sociedades de Assistência aos Lázaros e Defesa Contra a Lepra (Cunha, 2005, p.92).

O primeiro deles, o Asilo Santa Terezinha, na cidade de Carapicuíba, estado de São Paulo, Brasil, foi construído a partir de fundos da iniciativa privada e teve seus primeiros pavilhões inaugurados em 1927, ano em que recolheu as primeiras crianças (Monteiro, 1998, p.12). Nos anos que se seguiram, sobretudo a partir da liderança de Weaver frente à Federação, grande ênfase foi dada na criação de uma infraestrutura para o "controle social sobre os descendentes dos leprosos" (Santos, 2006, p.67). América Xavier da Silveira (1939, p.22), vice-presidente da FSALeDCL, entusiasticamente registrou, em 1939, que "pouco mais de um milhar de pequenos brasileiros, filhos sãos dos lázaros de nosso país, vão sendo livres do mal de Hansen, porque os Preventórios abrigam-nos conservando-lhes a saúde, educando-os e tornando-os futuros valores reais para sua pátria". Souza-Araújo (1954, p.426), por sua vez, anotou que "em 21 de dezembro de 1945 havia 2.410 crianças em 26 preventórios" espalhados pelo país, sendo a maioria das instituições fundada pela Federação das Sociedades de Assistência aos Lázaros e defesa contra a Lepra. ${ }^{21}$

Aspectos diversos dos preventórios brasileiros já foram apontados por alguns pesquisadores - distribuição pelo país, instrumentos disciplinares, estigmas produzidos, rotina asilar, memórias dos internos, imagens e filmes institucionais, entre outros temas (Gomide, 1991; Monteiro, 1998; Curi, 2002, 2010; Mattos, 2002; Maciel, 2007; Santos, 2010). Para os propósitos deste artigo, vale reforçar a ampla valorização feita pelas filantropas brasileiras quanto à necessidade de segregação dos doentes de lepra e dos filhos sadios de pais leprosos. A utopia do afastamento de corpos doentes do convívio social tornou-se realidade concreta ao longo do período 1930-1945. "Das quarenta instituições brasileiras de isolamento erigidas no século XX, 32 foram inauguradas na Era Vargas. Dos 36 preventórios brasileiros, trinta foram inaugurados no mesmo período. A Era Vargas responde por $80 \%$ das instituições de isolamento e $83 \%$ das instituições preventoriais" (Curi, 2010, p.258).

A valorização dos espaços preventoriais seguiu forte, mesmo depois de 1945. A reunião de encerramento da Segunda Conferência Nacional de Assistência Social aos Lázaros, no dia 17 de julho daquele ano, reiterou que, na falta de um lar "em condições morais e materiais adequadas", "a assistência ao filho sadio de lázaro" seria "realizada em estabelecimento preventorial especializado" (Serviço Nacional de Lepra, 1945, p.295). 
Na Argentina, o artigo 16 da Lei Aberastury, de 1926, garantia o prosseguimento da família pela convivência em residência conjunta na colônia de isolamento, uma vez pais e filhos fossem identificados como doentes. Porém, diferentemente do Brasil, o país vizinho proibiu o casamento entre leprosos ou entre leprosos e não leprosos pelo artigo 17 da mesma lei, fato que, segundo Miranda e Vallejo (2008, p.21), constituiu "o primeiro impedimento matrimonial de caráter eugênico legislado na Argentina". Independentemente dessa proibição, crianças foram geradas no interior das colônias de enfermos e enviadas para berçários ou asilos logo após o nascimento, espaços previstos, pelo artigo 18 da referida lei, para os filhos recémnascidos de leprosos. Ainda, o artigo 19 da Lei Aberastury garantia que os filhos saudáveis de pais submetidos a tratamento poderiam continuar suas vidas em escolas e oficinas comuns, mas seriam submetidos regularmente a inspeções médico-sanitárias.

Em 1939, a Argentina passou a contar com seu primeiro preventório, a Academia Hogar Esperanza, para "todas as crianças saudáveis, filhos ou conviventes de enfermos de lepra de toda a República" (Casares de Blaquier, 1939, p.17). O espaço constituía uma instalação provisória, pois, segundo a presidente do PL, futuramente as crianças seriam agrupadas em uma colônia agrícola, fato que ocorreu em 1941, quando foi inaugurada a Colônia Infantil Mi Esperanza, em Isidro Casanova, localidade próxima a Buenos Aires. Alguns anos depois da inauguração da Mi Esperanza, outro pequeno espaço de segregação foi criado: “Graças à preocupação e ação do Patronato de Leprosos da cidade, possuímos em Rosario um pequeno e bonito Preventório, onde quarenta crianças, filhos de enfermos de lepra, vivem felizes, completamente afastadas e salvas do perigo do contágio", afirmava entusiasticamente o doutor Salomón Schujman, chefe do Serviço de Leprologia do Hospital Carrasco. Ainda segundo o médico, o preventório Mi Esperanza, construído na Estação Casanova, província de Buenos Aires, podia ser considerado "a última palavra nesse tipo de estabelecimento" (Patronato de Leprosos, 1947, p.64).

Para a fundadora do PL, com a assistência aos filhos dos leprosos iniciou-se, na Argentina, "talvez o mais interessante dos capítulos da assistência social da lepra, porque é ele que pode 'torcer o destino dessas vidas', de outra maneira 'condenadas inexoravelmente'" (Casares de Blaquier, 1940, p.7, grifos do original). Ainda, segundo Casares de Blaquier (p.7),

Toda criança em contato com enfermo de lepra contagiosa, segundo os ditames médicos, deve ser segregada imediatamente e quando as condições da família não garantirem moradia com condições de vida propícias para o desenvolvimento material e moral, estabelecimentos especiais (asilos, casas, berçários) passarão a ser os responsáveis pelas crianças, com a vantagem de esses estabelecimentos permitirem melhor vigilância médica.

Leprólogos ilustres chegaram a dizer que, se tivessem que escolher como elemento mais eficaz na luta antileprosa entre o leprosário e o preventório, decidiriam por este último.

Memória do Patronato registrou que, durante o exercício de 1943, as crianças internadas na Colônia Infantil Mi Esperanza foram para lá enviadas pelo Departamento Nacional de Higiene, Dispensário do Hospital Muñiz, pelos Sanatórios-Colônia de General Rodríguez, Posadas, isla del Cerrito e pelas filiais do Patronato de Leprosos de Córdoba, Resistencia, Formosa, Rosario, Corrientes, Salta, La Plata, Concórdia e pela subfilial de Concepción del Uruguay. No total, a colônia possuía 161 internos e, devido ao fato de a capacidade máxima 
dos pavilhões já ter sido atingida, havia necessidade urgente de ampliação do preventório (Patronato de Leprosos, 1944a, p.67).

Em discurso durante a Semana da Lepra na Rádio El Mundo, em 7 de novembro de 1942, o doutor Tiburcio Padilla (Patronato de Leprosos, 1944a, p.109) enfatizou que a criação de colônias para filhos de leprosos, "mas ainda indenes", era o "único meio eficaz de exterminar este mal terrível que aflige aproximadamente trinta mil habitantes de nossa pátria. Esses trinta mil, serão, 40 mil ou 50 mil, se o governo e cada um de nós, não colaborar com seu próprio esforço". O doutor Padilla lembrava à audiência que a doença atacava preferencialmente crianças, portanto justificava-se a importância de espaços preventoriais. A despeito do discurso inflado do esculápio sobre a presença do mal de lázaro em solo argentino, é provável que os quatro espaços coloniais existentes até meados da década de 1940 não tenham albergado muito mais do que mil doentes; também é provável que a Colônia Infantil Mi Esperanza não tenha recolhido mais do que trezentas crianças até a subida de Perón ao poder, em 1946. Nesse ano, a Mi Esperanza possuía, além de uma "sala berçário", três pavilhões, sendo dois deles para os diferentes sexos, a partir dos 12 anos: o pavilhão Ana Bernal de Justo, para meninas, e o pavilhão Eduardo M. Zuberbuhler, para meninos. Contava ainda com um pavilhão de admissão que realizava uma espécie de longa quarentena, pois todos os ingressados na colônia deveriam ali permanecer três meses "antes de ser incorporados à vida de estudo e trabalho que ali se leva" (Patronato de Leprosos, 1946, legenda da foto 100).

\section{Considerações finais}

A história comparada aponta "diferenças e semelhanças importantes entre formações socioeconômicas, mantendo o foco na especificidade histórica" (Purdy, 2006, p.14). As semelhanças entre o PL e a FSALeDCL foram francamente mais fortes do que as diferenças, e as entidades, ao estreitar suas relações com os esculápios do campo da leprologia, legitimaram seu discurso filantrópico em prol do isolamento dos doentes de lepra. A divulgação da doença para amplas camadas sociais; a realização constante de campanhas para obtenção de recursos financeiros em prol da causa da lepra; e o controle e gerenciamento dos espaços para bebês, crianças e adolescentes filhos de leprosos, formataram indelevelmente a agenda das duas instituições entre a década de 1930 e meados da década seguinte. ${ }^{22}$

No que diz respeito à filantropia feminina para a causa da lepra, Brasil e Argentina diferiram não em termos de estratégias de atuação, mas sim em termos de resultados obtidos pelas estratégias adotadas. O contexto político argentino apresentou nítida falta de consenso das autoridades governamentais do país, em seus diversos níveis, sobre o isolamento de doentes. A oposição dos representantes das províncias em torno das leis criadas sobre tal questão, sobretudo o horror à presença de leprosários em territórios próximos às comunidades imaginadas como sadias, foi forte e constante durante quase toda a década de 1930. Tal fato referente às campanhas contra a lepra foi observado por Irene Molinari (2008, p.241), que apontou a resistência das populações locais quando se inteiravam da construção de sanatórios asilos "em suas imediações". Segundo ela, no período "não havia um trabalho conjunto e harmônico entre as autoridades sanitárias provinciais e comunais com o Departamento Nacional de Higiene, pois aquelas alegavam avassalamento em sua jurisdição por parte das 
autoridades nacionais". A viabilização prática da utopia da segregação de leprosos na Argentina foi tardia e acabou não alcançando o potencial numérico de internações sonhado por médicos e filantropas. ${ }^{23}$ No Brasil, também ocorreram discussões sobre a política segregacionista, e se nem todos estavam de acordo com ela (Curi, 2002; Monteiro, 2003; Cunha, 2005), houve, em contrapartida, certo consenso em torno do isolamento compulsório em colônias agrícolas para as formas clínicas consideradas abertas, contagiosas. ${ }^{24}$ Em 1924, já havia sido criado o Lazarópolis do Prata, no Pará, e, em 1926, quando a Argentina aprovava a Lei Aberastury, o Brasil inaugurava o segundo espaço para isolamento de doentes, a Colônia São Roque, no Paraná. ${ }^{25}$ Em 1946, o Brasil possuía 20.638 internos em seus diversos leprosários (SouzaAraújo, 1954, p.425).

Ao longo da década de 1930, a década de ouro no que se refere à atuação das entidades filantrópicas para os leprosos, os contextos políticos referentes ao processo centralizaçãodescentralização de poder seguiram diferentes nos dois países. Tal fato auxilia no entendimento do descompasso da Argentina no que tange à implementação de espaços coloniais para leprosos e preventórios para os filhos sadios de leprosos. Boris Fausto e Fernando Devoto lembram que, no Brasil, "os interventores federais, nomeados em substituição aos antigos governadores, como delegados do Executivo central, constituíram uma peça importante desse processo, barrando qualquer possibilidade de se criarem alternativas políticas". Na Argentina, por sua vez, no período de Justo, este "por contar com o apoio numa coalização de oligarquias provinciais, tinha menos espaço para intervir na política local" (Fausto, Devoto, 2004, p.244-245). Ainda quanto à ação do Estado, o alcance de sua intervenção e as políticas públicas adotadas, os autores destacam que a Argentina, quando comparada ao Brasil, em finais da década de 1930, foi francamente mais tímida: "Tanto Justo quanto Ortiz retomaram um modelo de Estado herdado do liberalismo argentino oitocentista, segundo o qual a intervenção do poder público deveria restringir-se à economia, como um ocasional instrumento anticíclico, mantendo-se à margem da esfera social" (p.259).

O rótulo estudo "transnacional", atualmente em voga no debate e crítica sobre o campo da história comparada, será válido para o resultado de futuras reflexões. Isso porque as fontes pesquisadas também demonstram, no que tange à medicina e à filantropia da lepra na Argentina e no Brasil, inequívocas e "múltiplas conexões e interdependências que [cruzaram] fronteiras" (Purdy, 2006, p.13). Tais questões não foram exploradas neste artigo e dizem respeito ao contato mais direto entre as filantropas argentinas e as brasileiras, em determinados momentos das trajetórias das entidades, como, por exemplo, na Segunda Conferência Panamericana de Lepra, em 1946, no Rio de Janeiro.

Mas desde já uma questão "transnacional" destaca-se e merece futuro aprofundamento: a forte conexão entre os médicos leprólogos ligados ao Patronato de Leprosos e o sistema de exclusão para os leprosos e seus filhos sadios do estado de São Paulo. De maneira geral, como já apontou Diana Obregón Torres (2002), não foi incomum os leprologistas latinoamericanos estabelecerem vínculos entre si, sobretudo a partir da década de 1930, em torno das campanhas antileprosas. Destaca a historiadora que, nesses vínculos criados ao redor da doença, argentinos e brasileiros trabalharam em conjunto na proposição de uma classificação sul-americana da lepra, recomendada na reunião pan-americana do Rio de Janeiro, em 1946: "Essa foi uma contribuição da ciência brasileira e argentina para 
a leprologia mundial ... A classificação sul-americana reconhecia duas formas polares (lepromatosa e tuberculoide) e um terceiro tipo clínico transitório e indeterminado" (p.326). Mas, além do trabalho conjunto no laboratório, os aspectos sociais e organizacionais dos leprosários, dispensários e preventórios paulistas atraíram sobremaneira os esculápios argentinos. Muitos deles visitaram colônias de isolamento paulistas e lá estagiaram (alguns com o patrocínio das filantropias do PL) nas décadas de 1930 e 1940 e tomaram tais espaços como modelos ideais a seguir em seu país: Pedro Baliña, José M.M. Fernández, Guilhermo Basombrio, Salomón Schujman, Arguello Pitt, Virgilio Etchevery, Nicolás Greco, Jeronimo Lopez e Alberto Nudemberg. Segundo a vice-presidente da FSALeDCL, América Xavier da Siveira (1944, p.35), o médico José M.M. Fernández considerou o modelo paulista de combate à lepra "perfeito e racional".

Os doutores argentinos ansiavam por uma política de saúde autônoma, forte e centralizadora, como a praticada por Salles Gomes à frente da chefia do Departamento de Profilaxia da Lepra no estado de São Paulo nas décadas de 1930 e 1940. Schujman (1937), médico do Hospital Carrasco, em Rosario, dedicou um livro inteiro ao estudo da administração paulista, La profilaxis antileprosa en el estado de São Paulo - informe elevado al Patronato de Leprosos de Buenos Aires sobre la gira de estudios realizada al Brasil. Além disso, é provável que a forte presença da eugenia no pensamento médico dos leprologistas do estado de São Paulo, questão já destacada nos estudos de Yara Monteiro, tenha tornado confortável o intercâmbio Argentina-Brasil, uma vez que os esculápios e as filantropas do Patronato de Leprosos possuíam vínculos explícitos com os ideais eugênicos. ${ }^{26}$

\section{NOTAS}

${ }^{1}$ Utilizam-se aqui os termos "lepra" e "leproso" por serem os termos correntes nos contextos históricos analisados.

${ }^{2}$ Tony Gould $(2005$, p.6) aponta, por exemplo, que a figura do leproso medieval evocava não apenas pavor, mas incluía também certa admiração, uma vez que evocava Christus quasi leprosus. Segundo o autor, para as pessoas que possuíssem a doença, o purgatório na terra garantia uma rota certa e segura ao paraíso após a morte.

${ }^{3}$ Nessa e nas demais citações de texto em língua estrangeira, a tradução é livre.

${ }^{4}$ Ricardo González Leandri (2000, p.434) afirma que na Argentina do final do século XIX e início do século XX, em virtude da necessidade de consolidação do Estado nacional, em virtude do forte impacto da imigração e do crescimento das multidões urbanas, emergiu a "figura do médico 'social'”. Um dos exemplos citados por Leandri para ilustrar suas ideias é, aliás, o doutor Mejía.

${ }^{5}$ O Departamento Nacional de Higiene foi criado no final de 1880.

${ }^{6}$ A lei n.11.410 modificou o artigo 33 da lei n.11.359, permitindo que os sanatórios-colônia fossem construídos a menos de cinquenta quilômetros de alguma localidade (Quiroga, 1964, p.97). Marisa Miranda e Gustavo Vallejo (2008, p.21) afirmam que a Lei Aberastury seguiu "sem maiores alterações, até sua revogação definitiva em 1983, evento que constituiu um dos últimos atos do governo ditatorial que assumira em 1976".

${ }^{7}$ Luciano Curi (2010, p.261) informa: "Em 1949, a profilaxia da lepra no Brasil foi finalmente definida em forma de lei ordinária. Trata-se da Lei n. 610 de 1949 que, em seus artigos, previa basicamente quatro medidas a serem tomadas com relação à lepra: isolamento compulsório de todos os acometidos; vigilância e controle de todos os suspeitos; notificação compulsória de todos os casos encontrados; afastamento dos menores indenes. Embora se trate de uma lei e não de um decreto do Executivo, ou seja, teoricamente uma espécie normativa de maior importância, ela não trazia nenhuma novidade com relação ao Regulamento de 1923".

${ }^{8}$ Sobre as virtudes de refletir a respeito das enfermidades na América Latina, Diego Armus (2002, p.12) apontou que as doenças possibilitam ao pesquisador visualizar "um repertório de práticas e construções 
discursivas que refletem a história intelectual e institucional da medicina". As enfermidades constituem "uma oportunidade para desenvolver e legitimar políticas públicas". María Silvia Di Liscia (2008, p.2325), ao fazer uma síntese dos estudos sobre a história das enfermidades e da saúde na Argentina, até 2008, apontou, entre outras questões, a necessidade de se ampliar o leque das pesquisas para além da tuberculose e da loucura, que seguem as mais estudadas; destacou a necessidade de aprofundamento no conhecimento de determinados órgãos-chave do país, como o Departamento Nacional de Higiene; e também reconheceu que várias instituições, lugares e agentes médicos seguem com poucos estudos, sobretudo os ligados à esfera privada.

${ }^{9}$ Uma vez articuladas com autoridades políticas de seus países (em maior ou menor grau) e, sobretudo, uma vez articuladas com autoridades médicas do campo da leprologia, as mulheres envolvidas com a assistência ao redor do mal de lázaro na Argentina e no Brasil revestiram-se de um amplo poder de atuação e afetaram o destino dos doentes e de seus familiares. Levando em consideração algumas ideias de Michel Foucault (1979) sobre poder, é possível afirmar que, no período analisado, a Federação das Sociedades de Assistência aos Lázaros e Defesa Contra a Lepra e o Patronato de Leprosos foram entidades com modos de ação complexos cujo poder não apenas expressou um caráter de potencialidade repressiva, mas também um caráter de produção de novas relações e de novas realidades.

${ }^{10}$ Os estudos de história comparada devem muito a Marc Bloch (1993), para quem seria tão legítimo estudar comparativamente sociedades próximas espacial e temporalmente quanto o contrário, isto é, seria possível comparar sociedades distantes geograficamente e com passados também distantes. Neste último caso, o estudo das influências recíprocas fica dificultado, e o historiador lança mão do recurso da analogia na comparação. Já no primeiro caso, é possível ao pesquisador perceber influências recíprocas de ambas as realidades estudadas dadas as contiguidades existentes. Particularmente sobre a lepra, há muitos aspectos a pesquisar em uma perspectiva mundial que permita, aliás, comparações entre diferentes países, próximos ou distantes geograficamente, sobretudo nos séculos XIX e XX. A partir do Décimo Sexto Congresso Internacional da Lepra, em Salvador, em 2002, os trabalhos ali apresentados - alguns deles depois compilados em publicação pela Casa de Oswaldo Cruz/Fundação Oswaldo Cruz no suplemento especial de 2003 da revista História, Ciências, Saúde - Manguinhos - revelaram que estudos diversos no campo das ciências sociais têm muito a contribuir para o entendimento da doença em uma perspectiva global. Temas os mais variados oferecem estimulantes reflexões, como a troca de informações médicas entre distintas nações (Robertson, 2003b); as representações sociais construídas sobre a moléstia ao longo dos anos (Oliveira et al., 2003); a comparação das experiências de confinamento em colônias de isolamento compulsório de diferentes países, conforme Cassandra White (2003) demonstrou em seu estudo sobre Curupaiti, no Rio de Janeiro, e Carville, na Louisiana, EUA, entre outros tantos aspectos. Como bem observou Jo Robertson, "Um mundo examinado pela 'lente' da história da lepra mostra intrincadas convergências de histórias nacionais, de políticas médicas, governamentais, e ainda de narrativas sociais sobre raça, classe e sexo" (Robertson, 2003a; destaque no original).

${ }^{11}$ Mesmo tendo o país criado algumas instituições de saúde a partir da fundação, já em 1823, da Sociedad de Beneficencia, estas abrangiam, sobretudo, mulheres pobres e dementes ou velhas e crianças órfãs ou expostas (Archivo General de La Nación, 1999).

${ }^{12}$ A expressão ‘década infame’ deriva da corrupção e das fraudes eleitorais do período. É comumente utilizada para o período que se inicia com o golpe militar de 6 de setembro de 1930, que destituiu Hipólito Yrigoyen do poder, e termina com o golpe militar que destituiu Ramón Castillo da presidência, em junho de 1943. Entre 1930 e 1944, a Argentina teve os seguintes presidentes: entre 1930 e 1932, governou o país José Félix Uriburu; entre 1932 e 1938, Augustín P. Justo; Roberto Marcelino Ortiz governou entre 1938 e 1942; Castillo entre 1942 e 1943; e Pedro Pablo Ramírez entre 1943 e 1944.

${ }^{13}$ A primeira edição do livro de Lee é de 1951.

${ }^{14}$ Existem leituras referentes à figura de Alice Tibiriçá e sua postura mais humanista em face da política do isolamento e que destacam sua oposição às arbitrariedades do Departamento de Profilaxia da Lepra (DPL) paulista sob a direção de Salles Gomes. Essas leituras baseiam-se nas memórias de Alice e em seus escritos, alguns compilados no livro Alice Tibiriçá: lutas e ideias, escrito, em 1980, por sua filha Maria Augusta Tibiriçá. O presente artigo, no entanto, centra seu foco nas ações da Federação das Sociedades de Assistência aos Lázaros e Defesa Contra a Lepra, sobretudo a partir da figura de Eunice Weaver.

${ }^{15}$ A autora ancora suas ideias na seguinte afirmação de Finlayson (citado em Eraso, 2009, p.11) "sempre houve o que agora chamamos de economia mista da assistência ... [e o Estado,] para a maior parte do século XIX, incluindo parte do século XX, não tem sido o agente mais importante". 
${ }^{16}$ Diana Obregón Torres (2002, p.26) afirma: “Os contagionistas encontraram inspiração na Idade Média e se dedicaram a escrever a história da lepra desde sua suposta aparição nos tempos bíblicos até o século XIX. Interessados em demonstrar o perigo da enfermidade e em justificar suas próprias medidas isolacionistas ... construíram uma identidade para a lepra não somente como uma doença microbiana específica, mas também como doença bíblica e medieval por excelência, intimamente ligada aos rituais religiosos de segregação".

${ }^{17}$ Ao final, Lutz (2004, p.510) concluiu: “as portas e janelas devem ser protegidas contra os mosquitos e devem ser feitas inspeções periódicas para excluir sua presença e impedir a formação de criadouros. Nenhuma profilaxia da lepra será completa sem o combate ao transmissor".

18 "Um dos grandes resultados da campanha de publicidade reside no fato de milhares de pessoas, após lerem os panfletos da Federação ou ouvirem Eunice Weaver no rádio, buscarem admissão nas colônias" (Federation..., 1951, p.16). Zilda Lima destaca que no Ceará, na década de 1940, os programas de rádio foram "extremamente" eficazes "no processo de segregação dos enfermos" (Lima, 2007, p.257).

${ }^{19}$ Dez dias após o encerramento da Conferência Nacional de Assistência Social aos Lázaros, em novembro de 1939, Eunice Weaver "comunicou ao presidente Vargas que, por decisão unânime, ficara estabelecido que apenas as Sociedades de Assistência aos Lázaros poderiam arrecadar donativos públicos para as vítimas do mal de Hansen e suas famílias. Ressaltava que essas entidades tinham a personalidade jurídica adequada, e deveriam ser autorizadas a desempenhar suas funções" (Santos, 2006, p.72).

${ }^{20}$ Sanglard (2008, p.213-224) refere-se a diversas atuações de Guilherme Guinle na área da saúde pública ao tempo de Carlos Chagas e, no caso específico da lepra, o empresário também patrocinou o Centro Internacional de Leprologia, no Rio de Janeiro; Monteiro refere-se a Julio de Mesquita e sua contribuição, via campanha realizada no jornal O Estado de São Paulo, para a viabilização da construção do Asilo Santa Terezinha, em Carapicuíba, abrigo para filhos de leprosos.

${ }^{21}$ Em 1951, panfleto em língua inglesa em homenagem a Eunice Weaver (compilado por uma de suas colaboradoras, não identificada) anotou que existiam seis mil mulheres filiadas nas 170 Sociedades de Assistência aos Lázaros e que muitas delas tomavam conta das quatro mil crianças que viviam nos trinta preventórios existentes (Federation..., 1951, p.9).

${ }^{22}$ Antonio Louzada (1942, p.427), docente da Faculdade de Medicina de Porto Alegre, registrou, em 1942: "A senhora Eunice Weaver, digna presidente da Federação das Sociedades de Assistência aos Lázaros e Defesa contra a Lepra, referindo-se às crianças nascidas no leprosário do Espírito Santo e recolhidas imediatamente ao preventório diz que são robustas, belas e alegres, e que de todas elas apenas uma faleceu de moléstia intercorrente. As outras são verdadeiros tipos eugênicos e não fariam má figura em qualquer concurso de robustez infantil".

${ }^{23}$ O doutor Arguello Pitt (1942, p.16), com base em informações do Departamento Nacional de Higiene, estimava que em agosto de 1941 havia na Argentina por volta de 4.592 casos da doença. No Brasil, o censo de 1927, realizado pela Inspetoria de Profilaxia da Lepra, apontava 12 mil casos e, no início da década de 1920, Belisario Penna (citado em Curi, 2010, p.251) calculava que o número de leprosos seria de 35.000, levando em consideração "o que hoje se chama de prevalência oculta". A população da Argentina, nos primeiros anos da década de 1940, somava em torno de 13 milhões (Moll, 1944, p.451); no Brasil, em 1940, segundo dados do Instituto Brasileiro de Geografia e Estatística, computava-se um total de 41 milhões de habitantes.

${ }^{24}$ Vale lembrar que no estado de São Paulo não houve distinção nesse sentido e, uma vez diagnosticada a presença da doença, independentemente de sua forma clínica, as autoridades médicas normalmente encaminhavam o indivíduo para a internação compulsória. Segundo Yara Monteiro (1995, 2003), o autoritarismo paulista se explica, entre outros fatores, pela forte presença da eugenia no pensamento médico. A historiadora também destaca que, no estado de São Paulo, o isolamento compulsório vigorou até 1967.

${ }^{25}$ Como apontado por alguns pesquisadores, já a partir de meados da década de 1910 não é possível reduzir a política de saúde brasileira ao rótulo campanhista. Segundo Luiz Antonio de Castro Santos (2004, p.252), depois de 1915, as questões de saúde pública tornaram-se mais complexas e "o alcance das ideologias de saneamento, naquele tempo, estendia-se para além dos maiores portos nacionais". Hochman (1993, p.55) aponta que o período varguista herdou "uma estrutura estatal e uma burocracia com razoável capacidade de atuação autônoma sobre o território nacional".

${ }^{26}$ Para ilustrar esse vínculo: em 1938, Hersilia Casares de Blaquier participou da mesa diretiva das Jornadas de Assistência Social, evento promovido pelo Instituto de Biotipología, Eugenesia y Medicina Social da Argentina (Patronato de Leprosos, 1944b, p.67). No ano seguinte, na Primeira Conferência de Assistência Social da Lepra, organizada pelo PL, Arturo Rossi, fundador e diretor daquele instituto, foi designado secretário-geral do evento (Patronato de Leprosos, 1940, p.58). 


\section{REFERÊNCIAS}

ALVARENGA, Antonia Valtéria Melo. Desenvolvimento e segregação: políticas de modernização e isolamento compulsório de famílias afetadas pela lepra no Piauí (19301960). Tese (Doutorado em História) - Instituto de Ciências Humanas e Filosofia, Universidade Federal Fluminense, Niterói. 2011.

AMENEDO, Cesareo.

La lepra: en la Provincia de Buenos Aires. La Plata: La Popular, 1906.

\section{ARGENTINA.}

Ministerio del Interior. Instrucciones para prevenir y combatir la lepra. Buenos Aires: Imprenta y Litografía de G. Kraft. 1912.

ARCHIVO GENERAL DE LA NACIÓN. Instituciones de la Sociedad de Beneficencia y Assistencia Social (1823-1952). Buenos Aires: Archivo General de La Nación. 1999.

ARGUELLO PITT, Luis.

Estado actual del problema de la lepra en Córdoba: epidemiología y profilaxis. Córdoba: Imprenta de la Universidad Nacional de Córdoba. 1942.

ARMUS, Diego et al.

Entre médicos y curanderos. Cultura, historia y enfermedad en la América Latina moderna. Buenos Aires: Norma. 2002.

BALIÑA, Pedro L.

Obstáculos que traban la implantación de la lucha antileprosa en nuestro país. Buenos Aires: A. Guidi Buffarini. 1933.

BECHLER, Reinaldo Guilherme.

Muito mais do que isolamento em questão: ciência, poder e interesses em uma análise das duas primeiras conferências internacionais de lepra - Berlim 1897 e Bergen 1909.

Temporalidades, Belo Horizonte, v.1, n.2, p.175-201. 2009.

BENCHIMOL, Jaime. L.; SÁ, Magali Romero. Adolpho Lutz and controversies over the transmission of leprosy by mosquitoes. História, Ciências, Saúde - Manguinhos, Rio de Janeiro, v.10, supl.1, p.49-93. 2003.

BLOCH, Marc.

Os reis taumaturgos: o caráter sobrenatural do Poder Régio. França e Inglaterra. São Paulo: Companhia das Letras. 1993.

CAPONI, Sandra.

Da compaixão à solidariedade: uma genealogia da assistência médica. Rio de Janeiro: Fiocruz. 2000.

CASARES DE BLAQUIER, Hersilia.

La Asistencia Social en la Lepra. Presente - Revista Oficial del Patronato de Leprosos, Buenos Aires, ano III, n.10, p.5-7. 1940.
CASARES DE BLAQUIER, Hersilia.

La campaña antileprosa en la República Argentina. s.l.: Presente. 1939.

COSTA, Dilma Fátima Avellar Cabral da. Entre ideias e ações: lepra, medicina e políticas públicas de saúde no Brasil (1894-1934). Tese (Doutorado em História) - Instituto de Ciências Humanas e Filosofia, Universidade Federal Fluminense, Niterói. 2007.

CUNHA, Vívian da Silva.

O isolamento compulsório em questão: políticas de combate à lepra no Brasil (1920-1940). Dissertação (Mestrado) - Casa de Oswaldo Cruz, Fundação Oswaldo Cruz, Rio de Janeiro. 2005.

CURI, Luciano Marcos.

Excluir, isolar e conviver: um estudo sobre a lepra e a hanseníase no Brasil. Tese (Doutorado) Faculdade de Filosofia e Ciências Humanas, Universidade Federal de Minas Gerais, Belo Horizonte. 2010.

CURI, Luciano Marcos.

"Defender os sãos e consolar os lázaros": lepra e isolamento no Brasil, 1935-1976. Dissertação (Mestrado) - Programa de Pós-graduação em História, Universidade Federal de Uberlândia, Uberlândia. 2002.

DI LISCIA, María Silvia.

Reflexiones sobre la 'nueva historia social' de la salud y la enfermedad en Argentina. In: Carbonetti, Adrián; González-Leandri, Ricardo (Ed.). Historias de salud y enfermedad en América Latina. Córdoba: Centro de Estudos Avanzados. p.15-47. 2008.

ERASO, Yolanda.

Mujeres y asistencia social en Latinoamérica, siglos $X I X$ y XX: Argentina, Colombia, México, Perú y Uruguay. Córdoba: Alción. 2009.

FAUSTO, Boris; DEVOTO, Fernando J.

Brasil e Argentina: um ensaio de história comparada (1850-2002). São Paulo: 34. 2004.

FEDERAÇÃO...

Federação das Sociedades de Assistência aos Lázaros e Defesa contra a Lepra.

Realizações de julho de 1935 a julho de 1945. Rio de Janeiro: s.n. 1945.

\section{FEDERAÇÃO...}

Federação das Sociedades de Assistência aos Lázaros e Defesa contra a Lepra. Histórico da cooperação privada no combate à lepra no Brasil. Relatório apresentado ao S. Ex. O Sr. Dr. Gustavo Capanema, Ministro da Educação e Saúde Pública pela 1a Vice-Presidente e Presidente em exercício, da Federação das Sociedades de Assistência aos 
Lázaros e Defesa Contra a Lepra Sra. America Xavier da Silveira. Rio de Janeiro: Papelaria Passos. 1938.

FEDERATION...

Federation of Societies for the Help of Victims of Leprosy.

Biographical notes (Eunice Weaver). Compiled by one of her fellow workers. Rio de Janeiro: s.n. 1951.

FIDANZA, Enrique P.

El problema actual de la lepra. Santa Fe: Universidad Nacional del Litoral. 1929.

FOUCAULT, Michel.

Microfísica do poder. Rio de Janeiro: Graal. 1979.

GOMIDE, Leila Regina S.

Órfãos de pais vivos: a lepra e as instituições preventoriais no Brasil: estigmas, preconceitos e segregação. Dissertação (Mestrado) - Faculdade de Filosofia, Letras e Ciências Humanas, Universidade de São Paulo. São Paulo. 1991.

GOULD, Tony.

Don't fence me in: leprosy in Modern Times.

London: Bloomsbury. 2005.

GRECO, Nicolás V.

El Patronato de Leprosos en la profilaxis integral de la lepra. Buenos Aires: E. Spinelli. 1942.

GUIJARRO, Enrique Diaz de.

El impedimiento matrimonial de enfermedad (matrimonio y eugenesia). Buenos Aires: Guillermo Kraft. 1944.

HAUSSEN, Doris Fagundes.

Rádio e política: tempos de Vargas e Perón. Porto Alegre: EDIPUCRS. 1997.

HERRERA DE FERNÁNDEZ, M.I. Franzini. El leproso y la sociedade. In: Patronato de Leprosos. Dolor y humanidad: cuentos, ensayos, parábolas. Buenos Aires: Patronato de Leprosos. p 43-45. 1937.

HOCHMAN, Gilberto.

Regulando os efeitos da interdependência: sobre as relações entre saúde pública e a construção do Estado (Brasil, 1910-1930). Estudos Históricos, Rio de Janeiro, v.6, n.11, p. 40-61. 1993.

LEANDRI, Ricardo González.

Miradas médicas sobre la cuestión social. Buenos Aires a fines del siglo XIX y principios del XX. Revista de Indias, Madri, v.60, n.219, p.421-435. 2000.

LEANDRO, José Augusto.

A hanseníase no Maranhão: rumo à Colônia do Bonfim. História, Ciências, Saúde - Manguinhos, Rio de Janeiro, v.16, n.2, p.433-447. 2009.
LEE, Elizabeth Meredith.

Leper's angel. In: Lee, Elizabeth Meredith. He wears orchids and other Latin American stories. Freeport, New York: Books for Libraries Press. 1.ed. 1951. p.43-49. 1970.

LIMA, Zilda Maria Menezes.

"O grande polvo de mil tentáculos": a lepra em Fortaleza (1920-1942). Tese (Doutorado)

- Instituto de Filosofia e Ciências Sociais,

Universidade Federal do Rio de Janeiro,

Rio de Janeiro. 2007.

LISBOA, Achilles.

A campanha contra a lepra no Amazonas. Facsimilado. Manaus: Edições Governo do Estado do Amazonas, Secretaria do Estado da Cultura, Turismo e Desporto. 1.ed. 1930. 2002.

LOUZADA, Antonio.

O problema da esterilização dos doentes de lepra. Revista Brasileira de Leprologia, São Paulo, v.10, n.4, p.421-430. 1942.

LUTZ, Adolpho.

Transmissão e profilaxia da lepra. In: Benchimol, Jaime; Sá, Magali Romero (Org.). Adolpho Lutz: obra completa. v.1, livro 2. Rio de Janeiro: Editora Fiocruz. p.509-510. 2004.

MACIEL, Laurinda Rosa.

"Em proveito dos sãos, perde o lázaro a liberdade": uma história das políticas públicas de combate à lepra no Brasil (1941-1962). Tese (Doutorado) - Instituto de Ciências Humanas e Filosofia, Universidade Federal Fluminense, Niterói. 2007.

MATTOS, Débora Michels.

"Fora do arraial": lepra e instituições asilares em Santa Catarina (1940-1950). Dissertação (Mestrado) - Faculdade de Filosofia, Letras e Ciências Humanas, Universidade de São Paulo, São Paulo. 2002.

MIRANDA, Maria Augusta Tibiriçá.

Alice Tibiriçá: lutas e ideias. Rio de Janeiro: PGLComunicação. 1980.

MIRANDA, Marisa; VALLEJO, Gustavo.

Formas de aislamiento físico y simbólico: la lepra, sus espacios de reclusión y el discurso médico-legal en Argentina. Asclepio. Revista de Historia de la Medicina y de la Ciencia, Madrid, v.LX, n.2, p.19-42. 2008.

MIRANDA, Marisa; GIRÓN SIERRA, Álvaro (Coord.).

Cuerpo, biopolítica y control social: América Latina y Europa en los siglos XIX y XX. Buenos Aires: Siglo XXI Editora Iberoamericana. 2009.

MOLINARI, Irene.

El Dr. José María Manuel Fernández. Medicina y ciencia al servicio de la erradicación del Mal de Hansen. In: Alvarez, Adriana; Carbonetti, Adrián 
(Ed.). Saberes y prácticas médicas en la Argentina: un recorrido por historias de vida. Mar del Plata: Eudem. p.227-251. 2008.

MOLL, Aristides A.

AEsculapius in Latin America. Philadelphia, London: W.B. Saunders Company. 1944.

MONTEIRO, Yara Nogueira.

Prophylaxis and exclusion: compulsory isolation of Hansen's disease patients in São Paulo. História, Ciências, Saúde - Manguinhos, Rio de Janeiro, v.10, supl.1, p.95-121. 2003.

MONTEIRO, Yara Nogueira.

Violência e profilaxia: os preventórios paulistas para filhos de portadores de hanseníase. Saúde e sociedade, São Paulo, v.7, n.1, p.3-26. 1998.

MONTEIRO, Yara Nogueira.

Da maldição divina à exclusão social: um estudo da hanseníase em São Paulo. Tese (Doutorado)

- Faculdade de Filosofia, Letras e Ciências Humanas, Universidade de São Paulo. 1995

NASCIMENTO, Dilene R. do; SANTA, Marcos Roma.

O método comparado em história das doenças. In: Nascimento, Dilene R. do; Carvalho, Diana Maul de; Marques, Rita de Cássia (Org.). Uma história brasileira das doenças, v.2. Rio de Janeiro: Mauad X. p.10-23. 2006.

OBREGÓN TORRES, Diana.

Batallas contra la lepra: estado, medicina y ciencia en Colombia. Medellín: Banco de la República, Fondo Editorial Universidad, Eafit. 2002.

OLIVEIRA, Maria Leide Wand-del-Rey de et al. Social representation of Hansen's disease thirty years after the term 'leprosy' was replaced in Brazil. História, Ciência, Saúde - Manguinhos, Rio de Janeiro, v.10, supl.1, p.41-48. 2003.

ORNELLAS, Cleuza P.

O paciente excluído: história e crítica das práticas médicas de confinamento. Rio de Janeiro: Revan. 1997.

\section{PATRONATO DE LEPROSOS.}

Reunión de presidentas de las casas filiales y subfiliales del Patronato de Leprosos de la República Argentina: primeira reunión del Patronato de Leprosos Internacional. Buenos Aires: Patronato de Leprosos. 1947.

PATRONATO DE LEPROSOS.

Presente - Revista Oficial del Patronato de Leprosos, Buenos Aires, ano 9, n.15. 1946.

PATRONATO DE LEPROSOS.

Memoria del Patronato de Leprosos. Buenos Aires: Patronato de Leprosos. 1944a.

PATRONATO DE LEPROSOS.

Sintesis de la obra del Patronato de Leprosos durante doce años por Julia Valentina Bunge de Uranga, Presidenta del Interior y de Prensa Tesorera General de la Institución. Buenos Aires: Guillermo Kraft. 1944b.

PATRONATO DE LEPROSOS.

Presente - Revista Oficial del Patronato de

Leprosos, Buenos Aires, ano 4, n.14. 1941.

PATRONATO DE LEPROSOS.

Primera Conferencia de Asistencia Social de la Lepra. Buenos Aires: Patronato de Leprosos, 1940.

PATRONATO DE LEPROSOS.

Presente - Revista Oficial del Patronato de Leprosos, Buenos Aires, ano 2, n.8. 1939.

PATRONATO DE LEPROSOS.

Dolor y humanidad: cuentos, ensayos, parábolas. Buenos Aires: Patronato de Leprosos. 1937.

PATRONATO DE LEPROSOS.

Memoria del Patronato de Leprosos correspondiente al ejercicio vencido en 31 de Diciembre de 1935. Buenos Aires: Patronato de Leprosos. 1936.

PATRONATO DE LEPROSOS.

Memoria del Patronato de Leprosos. Buenos Aires: Amorrortu. 1933.

PIÑERO GARCIA, Pedro P.

La lepra en Rosario: historia - epidemiología antecedentes contrarios a la instalación de una leprosería. Rosario: s.n. 1935.

PROVINCIA DE CORRIENTES.

La profilaxis de la lepra en el orden nacional y la provincia de Corrientes: cuestiones de orden público implicadas en el funcionamiento de Hospital de Aislamiento de Isla del Cerrito, como ejecución de la ley nacional 11.359. Corrientes: Imprenta del Estado. 1938.

PURDY, Sean.

A história comparada e o desafio da

transnacionalidade. In: Encontro da Associação

Nacional de Pesquisadores e Professores de História das Américas - ANPHLAC, 7., 2006, Campinas. Anais... Disponível em: http:// anphlac.org/upload/anais/encontro7/purdy.pdf. Acesso em: 15 jul. 2011. 2006.

QUIROGA, Marcial.

Historia de la lepra en la Argentina. Buenos Aires: s.n. 1964.

REVISTA DE COMBATE À LEPRA.

[Conselho Técnico]. Revista de Combate à Lepra, Rio de Janeiro: Federação das Sociedades de Assistência aos Lázaros e Defesa contra a Lepra, ano 9, mar.1943-jun.1944.

ROBERTSON, Jo.

Carta do editor. História, Ciências, Saúde -

Manguinhos, Rio de Janeiro, v.10, supl.1. 2003a. 
ROBERTSON, JO.

Leprosy and the elusive M. Leprae: colonial and imperial medical exchanges in the nineteenth century. História, Ciências, Saúde - Manguinhos, Rio de Janeiro, v.10, supl.1, p.13-40. 2003b.

ROMERO, Mariza.

Medicalização da saúde e exclusão social. Bauru: Edusc. 2002.

ROSEN, Georg. Uma história da saúde pública. São Paulo: Unesp. 1994.

SANGLARD, Gisele.

Entre os salóes e o laboratório: Guilherme Guinle, a saúde e a ciência no Rio de Janeiro, 1920-1940. Rio de Janeiro: Editora Fiocruz. 2008.

SANTOS, Cláudia Cristina dos.

Crianças indesejadas: estigma e exclusão dos filhos sadios de portadores de hanseníase internados no Preventório Santa Terezinha, 1930-1967. Dissertação (Mestrado) - Faculdade de Filosofia, Letras e Ciências Humanas, Universidade de São Paulo, São Paulo. 2010.

SANTOS, Luiz Antonio de Castro.

Poder, ideologias e saúde no Brasil da Primeira República: ensaio de sociologia histórica. In: Hochman, Gilberto; Armus, Diego. Cuidar, controlar, curar: ensaios históricos sobre saúde e doença na América Latina e Caribe. Rio de Janeiro: Editora Fiocruz. p.249-293. 2004.

SANTOS, Vicente Saul Moreira dos. Entidades filantrópicas e políticas públicas no combate à lepra: Ministério Gustavo Capanema (1934-1945). Dissertação (Mestrado) - Casa de Oswaldo Cruz, Fundação Oswaldo Cruz, Rio de Janeiro. 2006.

SANTOS FILHO, Lycurgo de Castro.

História geral da medicina brasileira. v.1. São Paulo: Hucitec; EdUSP. 1977.

SCHUJMAN, Salomón.

La profilaxis antileprosa en el estado de São Paulo. Informe elevado al Patronato de Leprosos de Buenos Aires sobre la gira de estudios realizada al Brasil. Rosario: Libreria y Editorial Ruiz. 1937.

\section{SERVIÇO NACIONAL DE LEPRA.}

Serviço Nacional de Lepra. Revista Brasileira de Leprologia, São Paulo, v.13, n.4, p.293-297. 1945.

SILVEIRA, America Xavier da.

The fight against leprosy in Brazil. Rio de Janeiro: Imprensa Nacional, 1944.
SILVEIRA, America Xavier da.

O combate à lepra no Brasil. Rio de Janeiro:

Divisão de Cooperação Intelectual/Ministério das Relações Exteriores, Resumo n.6, datilografado. 1939.

SOUZA-ARAÚJO, Heráclides Cesar de.

O problema da lepra no Brasil. Memórias do Instituto Oswaldo Cruz, Rio de Janeiro, v.52, n.2, p.419-441. Disponível em: http://memorias.ioc. fiocruz.br/pdf/Tomo52/tomo52(f2)_156-179.pdf. Acesso em: 18 set. 2011. 1954.

SOUZA-ARAÚJO, Heráclides Cesar de.

Lazarópolis do Prata: a primeira colônia agrícola de leprosos fundada no Brasil. Belém: Empreza Graphica Amazônia. 1924.

STEPAN, Nancy Leys.

A hora da eugenia: raça, gênero e nação na América Latina. Rio de Janeiro: Editora Fiocruz. 2005.

TABER, David.

Contribución a la profilaxis de la lepra en la República Argentina. La Plata: Universidad Nacional de La Plata. 1937.

VALLEJO, Gustavo.

La coerción disimulada: la propaganda radial de la eugenesia en la Argentina de entreguerras. In: Miranda, Marisa; Girón Sierra, Álvaro (Coord.). Cuerpo, biopolítica y control social: América Latina y Europa en los siglos XIX y XX. Buenos Aires: Siglo XXI Editora Iberoamericana. p.181-206. 2009.

VALLEJO, Gustavo; MIRANDA, Marisa (Comp.). Políticas del cuerpo: estrategias modernas de normalización del individuo y la sociedad. Buenos Aires: Siglo XXI Editora Iberoamericana. 2007.

VERANO, Alfredo Fernández.

Para una patria grande un pueblo sano. Buenos Aires: Talleres Gráficos de la Cía. Gral. Fabril Financeira. 1938.

VERONELLI, Juan Carlos.

Medicina, gobierno y sociedad: evolución de las instituciones de atención de la salud en Argentina. Buenos Aires: El Coloquio. 1975.

WHITE, Cassandra.

Carville and Curupaiti: experiences of confinement and community. História, Ciências, Saúde - Manguinhos, Rio de Janeiro, v.10, supl.1, p.123-141. 2003. 